\title{
PROSTITUCIÓN GENERAL: LA MUJER COMO BIEN COMÚN EN EL MARXISMO Y EN EL FEMINISMO
}

\section{GENERAL PROSTITUTION: WOMEN AS A COMMON GOOD IN MARXISM AND FEMINISM}

\author{
Belén Castellanos Rodríguez ${ }^{1}$ \\ Recebido em: 04/2018 \\ Aprovado em: 11/2018
}

\begin{abstract}
Resumen: Partimos del concepto marxista "comunidad de mujeres" y del lévistraussiano "intercambio de mujeres" para ver en ellos una estrategia de semejante base, que nos habla de la mujer como bien común. Tratamos de esclarecer bajo que modos de sociabilidad, de disimulo ideológico y de seducción, la mujer entra, como objeto en la lógica del don y del contra-don, más que en la puramente mercantil, como bien de producción. Desde esta explicación, aparecen ciertos rasgos de la vivencia sexual de las mujeres (aunque también de los hombres) alienada en una prostitución general, más o menos inconsciente, bajo la cual, no se reconoce, sin embargo, como trabajadora ni como sujeto del placer y del goce. Acompañados del feminismo radical, postestructuralista y postcolonial, seguiremos la pista de esta circunstancia y sus consecuencias.

Palabras clave: Comunidad de mujeres, intercambio de mujeres, Marx, marxismo, Engels género, feminismo, Kate Millet, Firestone, MacKinnon, Federici, Wittig, Davis, prostitución, sexualidad, sexo, trabajo sexual.
\end{abstract}

\begin{abstract}
We start from the marxist concept "community of women" and the levistraussian "exchange of women" to see in them a strategy of similar basis, which speaks of women as a common good. We try to clarify under what modes of sociability, ideological dissimulation and seduction, the woman enters, as an object in the logic of the gift and the counter-gift, more than in the purely commercial, as a production good. From this explanation, certain features of the sexual experience of women (although also of men) appear alienated in a general prostitution, more or less unconscious, under which, it is not recognized, however, as a worker or as a subject of pleasure and enjoyment. Accompanied by radical, poststructuralist and postcolonial feminism, we will keep track of this circumstance and its consequences.
\end{abstract}

Keywords: Community of women, exchange of women, Marx, marxism, Engels gender, feminism, Kate Millet, Firestone, MacKinnon, Federici, Wittig, Davis, prostitution, sexuality, sex, sex work.

\section{Cuando la comunidad es una comunidad de propietarios y la mercancía es la mujer.}

Cuando hablamos sobre lo común, solemos representarnos la bella imagen de los bienes

\footnotetext{
${ }^{1}$ Doctora en Filosofía (premio extraordinario de doctorado), Profesora-tutora en la UNED (Asturias), Profesora de Filosofía de educación Secundaria en Asturias (España), miembro del grupo de investigación de la UNED ONLENHER e investigadora en Ero-Mediterranean University Institute, en los departamentos de Historia y civilización y Género.
} 
compartidos y del disfrute colectivo de una lengua, de un patrimonio cultural, de un hábitat que nos acoge, de una racionalidad, o de aquellos rasgos que sentimos como constitutivos de un "nosotros", de una empatía y de un entendimiento posible.

Sin embargo, la conversión total y definitiva de toda cosa en enseres y provisiones, ha destinado al ser humano a su propia alienación, es decir, a una suerte de servidumbre voluntaria, de auto-instrumentalización que no deja lugar a la escritura de su espíritu, a la liberación de sus capacidades creativas ni a las posibilidades reales de un cuidado de sí.

Si bien el hombre ha devenido mercancía con la implantación del capitalismo, el negro fue traficado desde el amanecer de la modernidad y como acontecimiento definitorio de la misma. Pero la mujer parece haber sido inventariada al inicio de la civilización misma y, así, como acontecimiento de paso entre la naturaleza y la cultura. La historia de la civilización se narra como la historia de la incautación de la mujer o de la construcción de la mujer como regalo y del hombre como sujeto.

En Las estructuras elementales del parentesco, Claude Lévi-Strauss aportaba datos, trabajo de campo y gran fuerza interpretativa que daban sentido a la prohibición del incesto, el más antiguo de los vetos, el tabú primero, por el que el ser humano habría pasado a conformar una sociedad estructurada ¿Qué pudo ser lo que incitó al hombre a determinar algo así como el parentesco y, a su vez, a tipificar algo así como el incesto? Una ley tan antigua, cuya génesis se pierde en el pasado remoto y cuya excepción no ha sido observada en ninguna de las culturas, ni estacionarias ni históricas, parece indistinta del propio acontecer de la cultura misma, si con cultura nos referimos a la salida del ser humano de la animalidad.

No hay razones del todo claras para pensar que cierta conciencia de la muerte no se produzca en la mayor parte de los animales, aunque de otro modo y acompañada de emociones heterogéneas. En cambio, la prohibición del incesto parece ser tan universal para el humano como privativa del mismo, si bien recibe diversas concreciones relativas.

La teoría levistraussiana del intercambio de mujeres como envés y razón positiva de la prohibición del incesto no es un simple postulado sino el único que, hasta el momento, parece explicar plausiblemente tal interdicción, más allá de mitos eugenésicos anacrónicos e insostenibles. Bajo este descubrimiento, se iluminan determinadas estructuras económicas que no hallaban fácil justificación, como el fenómeno del regalo y su relación con los denominados "bienes de lujo". Disfrutar del sexo de las hijas o de la hermanas, expone Lévi-Strauss, sería como beber solo una botella de champaña. La mujer parece haber sido concebida como un bien de lujo, que sirve a la dinamización de las relaciones socio-económicas, a modo de presente en 
el cierre de pactos y como símbolo de su perdurabilidad. En el regalo se sigue la lógica del don y del contra-don. Las mujeres han sido menos sometidas a la compra-venta que al regalo. Se dona, como sabemos, bajo la expectativa de ser recompensado con otra mujer, aunque esta retribución llegue diferidamente.

\section{La heterosexualidad: la comunidad de los desiguales.}

La mujer se configura como bien de placer sexual y de producción. El goce de su cuerpo y el producto de su vientre, prometen una vida de alivio para las tensiones y de obtención de riquezas, susceptible de futuros intercambios. De esta manera, se estructuran, al mismo tiempo, el parentesco, la heterosexualidad y los roles de género (o lo que es lo mismo, los sexos). Afirma Judith Butler que es el orden heterosexual el que dispone el dualismo de género y este el que termina por configurar los sexos. El orden heterosexual es, antes que nada, una estructura de desigualdad, bajo la que el poder se reparte de modo dispar y la relación entre los integrantes se define, por ello, como relación de dominio. La heterosexualidad nombra la unión entre los diferentes y no entre los iguales. Los diferentes deberán responder como tales, por lo que las tareas, funciones y caracteres habrás de estar repartidos, dando lugar así a la codificación de género. Esta codificación no se hace sobre el sexo sino que inscribe, dualistamente, el sexo sobre el individuo ${ }^{2}$. Nuestra percepción está culturalmente cargada por el filtro de una serie de intereses sociales y la desigualdad entre los humanos no es anterior a estas lecturas. Ejemplo de ello es la naturalización de los esclavos en la antigüedad, la lectura racial de los individuos desde la colonización. Además, las relaciones son anteriores a los términos:

"... describo la heterosexualidad no como una institución sino como un régimen político que se basa en la sumisión y la apropiación de las mujeres. En situaciones desesperadas, como ocurría a siervos y esclavos, las mujeres pueden «elegir» convertirse en fugitivas e intentar escapar de su clase o grupo (como hacen las lesbianas) y/o renegociar diariamente, término a término, el contrato social" (WITTIG, 2006, p. 15)

"Es la opresión la que crea el sexo, y no al revés" (WITTIG, 2006, p. 22)

Esbozado este panorama, asistimos al desarrollo de toda una política sexual que

2 Ver A. Fausto-Sterling: Cuerpos sexuados. La política de género y la construcción de la sexualidad. Ed. Melusina. Barcelona, 2006. Para una visión completa y observación de la compleja argumentación científica, se recomienda la lectura no fragmentada de la obra. Para consultar la tipología en cinco sexos que la bióloga propone, se puede consultar específicamente el capítulo 4, “¿Por qué debería haber solo dos sexos?” 
sobrevisibiliza la voluntad y deseos del sujeto dominante, mientras que silencia los anhelos de las personas oprimidas, de las mujeres, anhelos que, por habitar en los márgenes y con muy poco oxígeno, brotarán en una diversidad mayor de vivencias y emociones, creciendo por donde pueden, acortándose por donde se les cierra el paso y haciendo de los objetos y las circunstancias eventuales, recursos de una perversidad casi polimorfa, a medio camino entre la adaptación y la confrontación, entre el pacto y el duelo.

Que a la mujer se le impida el acceso al estatuto de sujeto, no significa que se la quiera absolutamente pasiva, inerte o excesivamente maleable. Se exige de las inscritas como mujeres, cierta resistencia, un movimiento, una búsqueda, a fin de que propere en ella, el miedo, la sobreresponsabilidad, la auto-imagen, tan necesarias para promover la identificación con su trabajo y la naturalización e invisibilización del mismo como tal.

\section{La mujer: trabajadora por naturaleza.}

Las sociedades de clases han diseñado subjetividades crecientemente identificadas con el trabajo que desempeñan, hasta el punto de que, por arduo y fatigoso que éste fuera, acabara depositándose en él, el sentido mismo de la vida, el baremo de las autovalorizaciones, el orgullo de la existencia y la justificación de ausencias y defectos. Cuanto más intensa es la identificación del individuo con la tarea asignada, con mayor motivación asume su naturalidad, hasta que su socialización queda confundida en un hábito apenas retribuido. Si la mujer se ha identificado con su ternura, con su maternidad, con su disponibilidad, etc., no es porque no sean formas de trabajo, sino justamente porque lo son en toda regla.

Sin embargo, cuando una actividad se fiscaliza como trabajo y, así, como deber hacia los demás, y se apresa en horarios, ritmos, formatos y reglas, estandarizándose, pierde la frescura del descubrimiento, del juego, de la creatividad..., pues la eficacia y la acumulación como norma y finalidad, impiden toda demora que no se dirija hacia el automatismo. Es por eso, que instituyéndose el sexo, el cuidado y el amor, como trabajos para la mujer, muy difícilmente puede ésta, encontrar el amor propio y su modo gozoso de amar, el cuidado de sí y el estilo auténtico de defender, asistir y cultivar a los otros, o el deleite parasimbólico del abanico de sus posibilidades sexuales.

“... la principal razón por la que no podemos disfrutar del placer que nuestra sexualidad puede proporcionarnos es porque para las mujeres el sexo es un 
trabajo. Proporcionar placer al hombre es lo que se espera de toda mujer. La libertad sexual no nos ayuda en esto. Ciertamente es importante el que no se nos lapide si somos «infieles», o si se dan cuenta de que no somos «vírgenes», pero la «liberación sexual» ha incrementado nuestra tarea. En el pasado solo se esperaba de nosotras que criáramos a nuestros hijos. Ahora se exige que encontremos un trabajo asalariado, también que limpiemos la casa y tengamos niños y, además, que, al final de una doble jornada laboral, estemos listas para saltar a la cama y seamos sexualmente tentadoras" (FEDERICI, 2013. p. 47)

La "liberación sexual" no alisó el terreno para optar por el instinto o por la multiplicidad de posibilidades que nuestro deseo pueda imaginar y apetecer, sino que fortaleció la codificación y psiquiatrización sexual. Se insta a la mujer a acceder al encuentro genital con el hombre, bajo la amenaza de perder la ocasión de intimar, de "conocer" potenciales amores, pero, al mismo tiempo, cada aproximación sin resultado, sin el resultado socialmente reconocido y festejado, sin futuro familiar, continúa estigmatizando a la mujer.

\section{Alienación sexual y prostitución universal}

Nadie debería ser socialmente castigado por su experiencia sexual, pero hoy por hoy, urje que mujeres y hombres entiendan que no existe una carrera en la que tengamos que ofrecer una serie de movimientos tipificados de nuestro cuerpo, repetidamente, para hacernos valer y para entrar en la lista de personas carismáticas, ni que la edad ideal es la edad en la que exhibimos capacidad de reproducción o rendimiento eréctil.

Suele ocurrir que, como mecanismo de defensa, el oprimido se identifica con su tarea y advierte en ella su imprescindibilidad. En ello puede llegar alguien a basar toda su voluntad de poder. Así es como la capacidad creativa del deseo queda enquistada y hace víctima de la dominación, a la mujer, como parte instrumentalizada en el discurso del otro, pero también al hombre, expropiado, en esta compulsión, del derecho a la enunciación ya que, teniendo que querer lo que tiene que querer (poder de conquista, doblegar...), se lo exime del disfrute de más delicados encantos y se lo valora solo en cuanto que capaz de aparearse con un mayor número de personas y ocasiones.

Tanto hombres como mujeres estamos oprimidos en la alienación sexual. El capitalismo nos quita casi todos los medios y oportunidades para sentirnos reconocidos, para cuidar nuestro ego y para generar deseo. Esta situación de penuria, desprestigio personal y agotamiento, nos hacia la búsqueda de valorización en una reducida versión del sexo. Cuanto menos acceso tenemos a los saberes que posibilitan la sublimación (arte, deporte, investigación, militancia 
política, etc), más limitados nos vemos a la consumación sexual de nuestra energía y al intento insatisfactorio de subjetivarnos a través de la objetivación del otro. Sabiéndonos finitos, el miedo a la impotencia sexual, cercana e inevitable, conduce al coleccionismo, en el que tanto unos como otros, se auto-mercantilizan y se auto-fetichizan. No sucumbamos a esto. Reivindiquemos el derecho a otras tecnologías del yo, el acceso a los medios de sublimación y construyámonos en obras más intempestivas que los tanáticos y pobres encuentros sexuales mediados por las carencias de una economía libidinal y un eros embrutecido.

Desde esta perspectiva, esperamos que algún día, los hombres también reconozcan y se liberen de su alienación sexual. Los hombres comienzan a sentir su declive sexual a la edad en que las mujeres superan la fertilidad. Asumir esto como algo natural conduciría a disfrutar del aplacamiento de las tensiones que sacuden tan violentamente la juventud y a vivir tranquilo y con mayor autosuficiencia. El sexo no es algo central en la vida y si fuéramos libres para sentir y emocionarnos, todos reconoceríamos que nuestras expectativas están puestas en logros mayores y en emociones que alegran de modo más pleno. Esperamos que nuestros compañeros, los hombres, dejen de arriesgar su salud con viagras y hormonas porque lo que los hace deseables, queribles y valiosos, no es ni el número de mujeres ni de hombres con las que han mantenido relaciones sexuales, ni cuántas veces tienen sexo por año ni durante cuántos años. De hecho, muchas mujeres están esperando justo este descenso para poder encontrarse, como personas, de un modo más auténtico con los hombres y conocer las dimensiones de su alma que han quedado obscurecidas por el afán de mantenerse en algún tipo de podium sexual que les hace sufrir:

Spinoza diría: «No me interesa mucho que privilegien la sexualidad. No hace falta privilegiar la sexualidad porque signos equívocos hay por todas partes (...) «Aquello que constituye vuestra pesadumbre, vuestra angustia, es precisamente que viven en un mundo de signos equívocos. Y lo que yo, Spinoza, les propongo, es una especie de esfuerzo concreto para sustituir ese mundo de lo oscuro, de la noche, del signo equívoco, por un mundo de otra naturaleza. Este mundo, que no se opone al otro desde afuera sino que hay que extraerlo del primero con muchas precauciones, es un mundo de expresiones unívocas» (...) En este sentido, lo sexual viene del afuera. Entonces vayan, pero que no sea la mayor parte de ustedes mismos. Porque si lo es, en el momento en que llegue la muerte o aún más, cuando llegue la impotencia, la impotencia legítima de la edad, perderán la mayor parte de ustedes mismos. La muy curiosa idea de Spinoza es que finalmente la parte más grande de mí mismo será aquello que yo haya hecho durante mi existencia la parte más grande de mí mismo. Entonces, si hago de una parte mortal la parte más grande de mí mismo, al morir muero por entero. Y muero desolado (DELEUZE, 2006, p. 240). 
Resulta difícil medir en cuánto la "liberación sexual" ha descodificado el deseo de la mujer, y aflojado el claustro en el que su cuerpo y su dimensión afectiva se veían encerradas y en cuánto las ha encadenado aún con más fuerza y alienación al deseo del amo ¿Lograron lo que querían o unos derechos que no buscaban? La historia de los movimientos sociales cuenta con capítulos hermosos, con aventuras de solidaridad insospechada, de vínculos clandestinos e intensos, con momentos que nos permiten sabernos algo más que ejecutantes productivas de órdenes ajenas pero, a menudo, los finales nos han sabido a raro, a ser admitidas en un orden que hubiéramos querido subvertir ¿Queríamos ser objeto de la presunción de disponibilidad? ¿No ha redundado en el disimulo de tradicionales violencias (acosos, agresiones sexuales...)? ¿No es demasiada coincidencia que nuestra liberación sexual coincida con antiguas fantasías en lugar de romperlas y abrir un espacio de descubrimiento? Puede que no esté de más preguntarse qué derechos nos pesan, pues en el discurso de los derechos hallemos ahora la medida de las imposiciones acalladas.

\section{El matrimonio burgués y la comunidad de mujeres en Marx y Engels.}

La liberación sexual no es un tema nuevo. Karl Marx imaginó cómo podría darse un modo tal de relación entre los sexos, en que el amor no supusiera una prisión y la mujer no fuera capturada dentro de un contrato desigual ni como vehículo de la acumulación de capital. En este sentido, presumía que, a la caída de la propiedad privada de los medios de producción, la mujer quedaría liberada del yugo del rico, del propietario, a través de una transvaloración de los afectos.

El burgués, que no ve en su mujer más que un simple instrumento de producción, al oírnos proclamar la necesidad de que los instrumentos de producción sean explotados colectivamente, no puede por menos de pensar que el régimen colectivo se hará extensivo igualmente a la mujer. No advierte que de lo que se trata es precisamente de acabar con la situación de la mujer como mero instrumento de producción. Nada más ridículo, por otra parte, que esos alardes de indignación, henchida de alta moral de nuestros burgueses, al hablar de la tan cacareada colectivización de las mujeres por el comunismo. No; los comunistas no tienen que molestarse en implantar lo que ha existido siempre o casi siempre en la sociedad (...) En realidad, el matrimonio burgués es ya la comunidad de las esposas (...) Por lo demás, fácil es comprender que, al abolirse el régimen actual de producción, desaparecerá con él el sistema de comunidad de la mujer que engendra, y que se refugia en la prostitución, en la oficial y en la encubierta (MARX; ENGELS, 2013, p. 74).

El gran sistema capitalista muestra a menudo enormes capacidades para dar la vuelta a 
las demandas sociales, absorber los movimientos anti-sistema y poner todo ello a funcionar en su favor. El derecho a follar se convierte, con la liberación sexual, en la obligación de follar. Se impone la disponibilidad sexual de la mujer como pago a su inserción en el espacio público, en las calles, en los bares, en los gimnasios y en otros lugares de ocio. La mujer está, casi irremediablemente condenada a manejar el flirteo y a denegarlo, en último caso, muy sutilmente, tanto, que la tarea de salir bien parada de este juego al que se la obliga a participar, conlleva todo un arte para el que habrá debido cosechar numerosos dolores de cabeza y al que habrá tenido que dedicar un alto porcentaje de las conversaciones con su madre, su abuela y sus amigas, sin que acabe de encontrarse una solución óptima. Aquellas que han tenido que esforzarse como nadie buscando recursos propios para desarrollar la autovalorización que el reconocimiento social no les procura, deben velar continuamente por el ego masculino (bien turgente y abastecido), cuidando cada palabra y cada reacción, a fin de que éste no resulte dañado, cuestionado, ligeramente rozado, a fin, en todo caso, de no levantar tempestades con una negativa de más o con un sobreentendido de menos. Esto es un trabajo, si no, más bien, una tortura rutinaria.

Se puede decir que todas las mujeres, casadas o no, deben efectuar un servicio sexual forzoso (...) Las mujeres son muy visibles como seres sexuales, pero como seres sociales son totalmente invisibles, y aun así deben hacerse lo más pequeñas posible y deben siempre disculparse (WITTG, 2006, p. 26).

La categoría de sexo es la categoría que une a las mujeres porque ellas no pueden ser concebidas por fuera de esa categoría. Sólo ellas son sexo, el sexo, y se las ha convertido en sexo en su espíritu, su cuerpo, sus actos, sus gestos; incluso los asesinatos de que son objeto y los golpes que reciben son sexuales. Sin duda la categoría de sexo apresa firmemente a las mujeres (WITTG, 2006, p. 28).

Puede que el programa de liberación sexual, la píldora anticonceptiva, la ligadura de trompas o incluso el aborto, no fueran nunca un proyecto feminista sino más tecnología machista para un mundo contemporáneo, en el que el intercambio de mujeres no sea de a una, sino en una extensión y en una intensión indefinida en la que el deseo de la mujer (y tal vez el del hombre también) haya sido secuestrado o sobornado con más de un dispositivo (psiquiatrización de la abstinencia sexual, psicologización del celibato, ostracismo social de la soltera, etc.). A este intercambio masivo de mujeres lo denomina Marx "comunidad de mujeres".

M. E..., fabricante, me ha hecho saber que él emplea exclusivamente a 
mujeres en sus puestos mecánicos; da preferencia a las mujeres casadas, sobre todo a aquéllas que tienen familia numerosa; son más atentas y más disciplinables que las mujeres solteras, y además están obligadas a trabajar hasta la extenuación para procurarse los medios de subsistencia necesarios (Ten Hour's Factory Bill, The Speech of Lord Ashley. London, 1844) (MARX, 2008, s/p).

Engels afronta la cuestión de la mujer y preludia la teoría del intercambio de mujeres, dejando ver, a su vez, su apuesta por el amor libre y su agudo romanticismo. El intercambio de mujeres se extiende a las sociedades modernas a través de la clausura afectiva dentro de la clase social, como más adelante entreveía Lévi-Strauss:

En nuestros días hay dos maneras de concertar el matrimonio burgués. En los países católicos, como antes, los padres proporcionan al joven burgués la mujer que le conviene, de lo cual resulta naturalmente el más amplio desarrollo de la contradicción que la monogamia encierra: exuberante heterismo masculino y exuberante adulterio femenino. Y si la Iglesia católica abolió el divorcio, es probable que fuese por haber reconocido que frente al adulterio, como frente a la muerte, no hay remedio que valga. Por el contrario, en los países protestantes la regla general es conceder al hijo del burgués más o menos libertad para buscar mujer dentro de su clase. Por ello el amor puede ser, hasta cierto punto, la base del matrimonio, y para guardar las apariencias se supone siempre que es así, lo que está muy en consonancia con la hipocresía protestante (ENGELS, 2017, p. 30).

Pero en ambos casos, el matrimonio se funda en la posición social de los contrayentes, y por tanto, siempre es un matrimonio de conveniencia. También en ambos casos este matrimonio de conveniencia se convierte a menudo en la más vil de las prostituciones, a veces por ambas partes, pero mucho más habitualmente en la mujer, que sólo se diferencia de la cortesana ordinaria en que no alquila su cuerpo a ratos, como una asalariada, sino que lo vende de una vez para siempre, como una esclava. (ENGELS, 2017, 31)

Respecto al matrimonio, hasta la ley más avanzada se da enteramente por satisfecha desde el punto y hora en que los interesados han inscrito formalmente en el acta su libre consentimiento. En cuanto a lo que pasa fuera de las bambalinas jurídicas, en la vida real, y en cuanto a cómo se expresa ese consentimiento, no es algo que inquiete a la ley ni al jurista. Y sin embargo, la más sencilla comparación del derecho de los distintos países debería mostrar al jurisconsulto lo que representa el libre consentimiento. En los países donde la ley asegura a los hijos la herencia de una parte de la fortuna paterna y donde, por consiguiente, no pueden ser desheredados (Alemania, los países que siguen el derecho francés, etc.), los hijos necesitan el consentimiento de los padres para contraer matrimonio. En los países donde se practica el derecho inglés, donde el consentimiento paterno no es condición legal del matrimonio, los padres gozan también de absoluta libertad de testar y pueden desheredar a su antojo a los hijos (ENGELS, 2017, p. 50).

El amor sexual solo habría de ser posible entre los desposeídos, si bien la ideología 
monogámica imprimiría un trato decadente en la relación entre los sexos:

En las relaciones con la mujer, el amor sexual no es ni puede ser una regla excepto entre las clases oprimidas (en nuestros días, el proletariado), estén o no esas relaciones autorizadas oficialmente. Pero en este caso también desaparece el fundamento de la monogamia clásica, dado que faltan por completo los bienes de fortuna, para cuya conservación y transmisión por herencia se instituyeron precisamente la monogamia (...) Por eso, el heterismo y el adulterio, eternos compañeros de la monogamia, desempeñan aquí un papel casi nulo (ENGELS, 2017, p. 50).

\section{Prostitución general y economía sumergida}

Una de sus observaciones sociológicas más brillantes e innovadoras, de las que muchas feministas beben desde los 70 hasta nuestros días, es la que evidencia un deterioro del poder de la mujer en las sociedades modernas, en las que el trabajo doméstico se privatiza y queda sumergido bajo el yugo masculino:

En el antiguo hogar comunista, que comprendía numerosas parejas conyugales con sus hijos, la dirección del hogar, confiada a las mujeres, era también una industria socialmente tan necesaria como el cuidado de proporcionar los víveres, cuidado que se confió a los hombres. Las cosas cambiaron con la familia patriarcal y aún más con la familia individual monogámica. El gobierno del hogar perdió su carácter social. La sociedad ya no tuvo nada que ver con ello. El gobierno del hogar se transformó en servicio privado; la mujer se convirtió en la criada principal, sin tomar ya parte en la producción social (ENGELS, 2017, p. 32)

Del mismo modo, deshace el prejuicio por el que todavía se sigue diciendo que las mujeres acaban de salir al mercado laboral, describiendo las condiciones en las que operan las trabajadoras del sector textil o relatando la cotidianidad de las mujeres en el sector minero, que las emplea para labores en la superficie solo después de que en 1842 se prohibiera su descenso bajo tierra. Como actualmente afirma Silvia Federeci, la incorporación de la mujer al trabajo industrial es tan antigua como el propio capitalismo y en modo alguno mejoró las condiciones del colectivo sino más bien al contrario:

Ya hemos visto eso en la fabricación de encajes, y ahora tenemos en las tiendas de moda de Londres una nueva prueba en apoyo de esta afirmación. Estos establecimientos emplean a gran número de chicas jóvenes - hay, según se dice, un total de 15.000 - que viven y comen en la casa, la mayor parte originarias del campo, y son así esclavas completas de la patronal. Durante la temporada alta, que dura en torno a cuatro meses al año, la duración del trabajo 
llega, incluso en las mejores casas, a quince horas y, si surgen asuntos urgentes, dieciocho; pero, en la mayor parte de las casas, se trabaja durante este período sin ninguna fijación de tiempo, aunque las chicas no tienen más de seis horas, a veces tres o cuatro, e incluso dos horas sobre veinticuatro para descansar y dormir, y trabajan de diecinueve a veinte horas por día, cuando no son forzadas - cosa que ocurre con bastante frecuencia- a pasar itoda la noche trabajando! El único límite de su trabajo es la incapacidad física absoluta de seguir con la aguja un minuto más (ENGELS, s/d, p. 293).

El fabricante es, en este aspecto también, el amo del cuerpo y de los encantos de sus obreras. El despido es un castigo bastante fuerte como para triunfar, en nueve casos sobre diez, sino en noventa y nueve casos sobre cien, sobre los escrúpulos de chicas que ni los tienen o que no tienen gran disposición a la castidad. Si el patrón es pequeño- y el informe de la comisión cita numerosos casos- su fábrica es al mismo tiempo su harén... (ENGELS, s/d, p. 221)

La apuesta de Marx y Engels no es la comunidad patente de mujeres sino, unidos al romanticismo más revolucionario, el amor libre, algo que vislumbran bajo las condiciones de posibilidad de una sociedad comunista. En cambio, en una sociedad de clases, en la que las condiciones y la construcción de emociones y afectos pivota en torno al poder de la propiedad privada y al fetichismo de la mercancía, que incluye la performance de género y el productomujer, puesto en el escaparate, manifestando y ocultando las penurias, explotación y sometimiento que habitan tras el magnetismo y el glamour de su presentación. Este fetichismo de la mercancía, que incluye y forcluye la subjetividad de la mujer, se desenvuelve a través de toda una política sexual. Así tituló su obra central y clásico del feminismo, Kate Millet, Política sexual, con la que abre la década de los 70, fructífera en la reflexión acerca de la vivencia femenina del amor. Con esta oleada de nueva filosofía de género, se desenmascara el amor como trabajo encubierto de la mujer. Con ello, se abre todo un nuevo mundo de posibilidades para la introspección de la mujer y para la conquista de su conciencia de clase, pudiendo resituarse, y advertir sus lugares en el conjunto de la producción. Todavía destacaremos más la ácida escritura con la que Shulamith Firestone deconstruye, con firmeza y bocanadas del mejor materialismo, el amor sexual y su papel explotador en la era capitalista:

Los hombres liberados necesitaban pollitas guapas que pudieran adaptarse a su nuevo estilo de vida; las mujeres hicieron la prueba. Ellos necesitaban sexo; las mujeres cumplieron con su parte. Pero esto era todo cuanto necesitaban de las mujeres. Si a una chica se le metía en la cabeza pedir alguna compensación anticuada a cambio, era una retrógrada, una retorcida o, aún peor, una frustrada. Una chica tenía que aprender a ser independiente a fin de no convertirse en una carga para su hombre (FIRESTONE, 1976, p. 41).

La cultura masculina era y sigue siendo parásita y se alimenta de la energía emocional de las mujeres sin reciprocidad" (FIRESTONE, 1976, p. 160). 
¿Por qué toda la alegría y excitación ha sido concentrada y unificada en una parcela estrecha y difícil de alcanzar de la experiencia humana, dejando baldío todo lo demás? Cuando exigimos la eliminación del erotismo, no nos referimos a la eliminación del goce y excitación sexuales, sino a su redifusión sobre toda la trama de nuestras vidas (FIRESTONE, 1976, p. 196)

Puede que la liberación sexual sea un contrasentido, si admitimos el escenario sexual como teatro determinado por la ideología de la dominación y cargado por un imaginario que funciona a través de la plasticidad y redes del inconsciente. Tomar a alguien bajo el único interés del intercambio erótico, es un modo fuerte de desprecio. Resulta difícil imaginar cómo la liberación sexual, relativizando la importancia de la unión íntima, podía empoderar en modo alguno a la mujer, que habrá pasado de retener, dosificar y regular esa capacidad sexual con la que podía intercambiar cierta estabilidad económica, a devaluar hasta la nada esa labor afectiva, que se dispensaría masivamente.

Regalar sexo, cuidados, amor, a cambio de nada supone redoblar la posición de esclava. Si tan siquiera, la liberación sexual hubiera supuesto un descubrimiento de la sexualidad de la mujer y un desplazamiento de la atención hacia el saber de su erogeneidad y de sus placeres, si tan solo hubiera servido para desmontar mitos como el del orgasmo vaginal, el del multiorgasmo, el del mayor tiempo de la duración del coito como favor para ella (¡ella! que tantas veces fingió en la intimidad para que aquello terminara lo antes posible), si hubiera permitido a la mujer acercarse a su propio deseo, a los medios de producción de su propio deseo, en lugar de multiplicarse como consuelo express del hombre, habríamos conseguido dar un paso hacia algún lado distinto de la simple comunidad de mujeres o prostitución general abaratada.

En la misma línea de Foucault, Firestone pone en evidencia la hipersexualización social, la intensidad con la que los dispositivos ideológicos del Estado (focos públicos de poder) seducen y excitan continuadamente a los individuos, unidimensionalizándolos, tanto a mujeres, devenidas bienes de producción sexual sobre-explotados y desvalorizados, como a los hombres, alienados en una incansable carrera de conquistas o azañas sexuales, en ausencia de las cuales creen perder su virilidad, su energía e incluso la chispa de la vida, hasta no poder distinguir la ausencia de sexo de la ausencia de vida. El poder ha diseñado el espejismo sexual orientando tras él la búsqueda de sentido y encerrando el deseo en esta forma única de encuentro con el otro, de reconocimiento, de interpretación del gesto, de vigor o salud, de creatividad, de construcción de proyectos colectivos, de modos de ocio. Todo ha llegado a instrumentalizarse hacia el éxito sexual, pues alzándose éste en baremo de logro personal, se asegura la 
permanencia de la estructura heterosexual de parentesco, el reparto de roles y, en definitiva, la educación en la desigualdad. Se asegura que haya mujeres y que haya hombres, que haya esclavos y que haya amos y que esta mutua dependencia resulte existencial y que tanto unos como otros, luchen entre sí para alcanzar la posición de privilegio, para lo cual habrán de pasar los filtros del poder y dar por buena la máquina de desigualdad. Mantenerse en el poder implica la permanente renuncia al auténtico poder, a la potencia, a la capacidad de obrar y de generar nuevos códigos y modos de habitabilidad más incluyentes y, por ello, lazos de cooperación más robustos.

Sin embargo, para luchar contra la esclavitud, necesitamos reconocerla, sabernos en la posición marginizada en la que actuamos y desde la que se nos lee. Para ello, debemos emplear un orgullo de clase, basado en la conciencia de nuestra necesidad, del carácter irreemplazable de nuestra aportación social, de la dignificación de nuestro trabajo (incluido el del amor: cuidados, entretenimiento, consuelo, animación, etc.) y de la interdependencia que las mujeres hemos, para bien, tejido, en la aventura de la supervivencia. Tal orgullo de clase riñe con el orgullo simbólico-culturalista, erguido en función de la competitividad y el deseo de dominio. La lógica de dominación nos somete a todos. Eso es lo que deben comprender nuestros compañeros masculinos y eso es, también, lo que deben recordar nuestras compañeras en ascenso social.

Una de las mayores urgencias reside en este trabajo que es un trabajo social, de reflexión comunitaria pero también de introspección e incluso de reubicación de nuestras expectativas. Caer en la trampa de la eterna promoción, del triunfo aspiracional, del reconocimiento espectacular, o de la perfecta adaptabilidad a los requerimientos de un sistema en el que el mismo agente se encarga de nombrarnos y de expropiarnos, de encumbrarnos y de exprimirnos, es caer en la trampa en la que todavía hoy los hombres se hallan enredados. Es importantísimo recordar a Heidegger acerca de la inevitable objetivación del explotador:

Desde el momento en el que lo no oculto aborda al hombre, no ya siquiera como objeto sino exclusivamente como existencias, y desde el momento en que el hombre, dentro de los límites de lo no objetual, es ya sólo el solicitador de existencias, entonces el hombre anda al borde de despeñarse, de precipitarse allí donde él mismo va a ser tomado sólo como existencia. Sin embargo, precisamente este hombre que está amenazado así se pavonea tomando la figura del señor de la tierra. Con ello se expande la apariencia de que todo cuanto sale al paso existe sólo en la medida en que es un artefacto del hombre. Esta apariencia hace madurar una última apariencia engañosa. Según ella parece como si el hombre, en todas partes, no se encontrara más que consigo mismo (...) Sin embargo, la verdad es que hoy el hombre no se encuentra en ninguna parte consigo mismo, es decir, con su esencia 
(HEIDEGGER, 2001, p. 25).

Por ello, la lucha feminista debe ser una lucha anticapitalista que no busque la complaciente nivelación con el hombre sino el fin de las lógicas de dominación instaladas a través de la institución heterosexual y heterocéntrica, de la estructuración consumista de la sociedad, de la adultocracia y del productivismo, en favor de constructivismos que no castren salomónicamente nuestro proceso de sexualización y nos permita gozar a todos de los registros masculinos y femeninos no privativos, hasta su posible y esperable difuminación y que nos permita enriquecernos fuera de los estrechos límites de la laboralización, para lo cual, resulta imprescindible el actual reconocimiento de los diversos modos de trabajo y del carácter productivo del mal llamado "amor".

La batalla por un mundo que permita mostrar la vulnerabilidad, la dependencia y la mortalidad tanto del individuo como de la especie es vital para un feminismo revolucionario que no vaya a convertirse, simplemente, en plataforma oportunista para habilitarse en la zona blanca y masculina y abandonar a los negros, a las mujeres, a los animales, en definitiva, a nuestros hermanos de la historia no contada de los márgenes. Posibilitar un devenir-mujer, un devenir-animal, un devenir-negro, es nuestra potencia más brillante. En las antípodas, viven las abejas reinas y la debilidad vergonzante:

La obsesión que recorre a las minorías, en su temor de que pudieran ser ciertas las fábulas entorno a su inferioridad, alcanza proporciones inusitadas en la inseguridad femenina. Algunas mujeres consideran tan inadmisible su posición inferior, que terminan por reprimirla y negarla rotuntamente (MILLET, 1995, p. 122).

La sociedad concede a unas cuantas mujeres una posición superior para que ejerzan sobre las demás una especie de censura cultural (...) Estas suelen verse obligadas a compensar su encumbramiento demostrando deferencia mediante una serie de declaraciones rituales, y a menudo muy cómicas, que en su expresión más típica constituyen votos de 'feminidad', es decir, de complaciente docilidad unida a un fuerte anhelo de sumisión al dominio masculino (MILLET, 1995, p. 123)

\section{El malestar en la familia y otros modos de prostitución.}

En el fondo, un malestar acompaña a la civilización del intercambio de mujeres. Ellas no desean la violenta instrumentalización con la que devienen mercancía sexual y, si acaso este imaginario ha sido inyectado sobre nuestras subjetividades, se esfuerzan en disimularlo o hacerlo pasar por un contenido teatral de su libertad o juego de seducción. En cambio, como 
apuntaba Wilhelm Reich, la revolución sexual, tomada en sentido auténtico, no sería otra cosa que el proceso de abolición de la familia. Reich afirmaba que la familia reprime la vida sexual de los hijos, disponiendo a la neurosis y que, bajo el sistema capitalista, desconocemos las condiciones sociales de una existencia amorosa satisfactoria. Con la represión sexual, se instituye la represión cognoscitiva, intelectual, técnica, motora, etc. Cuando se reprime en el niño y la niña (o en la mujer) su curiosidad sexual y su vida sexual se están reprimiendo colateralmente muchos otros potenciales de origen pulsional, como el ejercicio intelectual, el deporte, la disposición crítica, etc. Reprimir sexualmente al individuo significa amansarlo en todos los sentidos, castrar todo aquello que pueda resultar subversivo para el orden establecido. Así, la verdadera finalidad de la represión sexual es política. La sociedad capitalista, por medio de la publicidad y de la ideología, en la que utiliza motivos sexuales, obtendría provecho del tabú para lograr manejar el inconsciente de las masas y convertirlas en consumidoras. Reprime y seduce. Son dos caras de la misma moneda. La miseria conyugal no se agota en la divergencia de la pareja, sino que se derrama sobre los hijos. También la restricción sexual que los adultos se imponen, recae sobre los hijos. El transcurso de la vida familiar acumula un enorme odio que, consciente, puede desencadenar una poderosa fuerza revolucionaria volcado sobre sus causas reales, pero, reprimido, conduce a exteriorizaciones inversas como la obediencia ciega o la angustia social ${ }^{3}$. Además de la clásica reivindicación comunista en torno a la colectivización de los medios de producción, cabría señalar, como modo fundamental de construcción de un buen común, de un común no cosificador ni explotador ni destructivo, la necesidad de colectivizar los medio de sublimación, dando acceso, a toda persona, a los recursos que permiten una sana economía libidinal, una capacidad creativa y abrirle una fuente de autovalorización verdaderamente rica y acorde con sus humanas capacidades, de tal suerte que la alienación sexual pudiera decaer en beneficio de una multitud de vías de transcendencia que nos permitan conciliarnos con nuestra finitud.

La represión sexual y la hipersexualización son lo mismo: se trata de hacer ver que las relaciones sexuales con cierta gente y bajo determinado pacto, son repugnantes, y que las relaciones sexuales con otra gente y bajo determinado pacto son la panacea, el mayor de los bienes del universo y la más plena realización personal. Y lo que pasa es que no es ni una cosa ni la otra salvo para una sensibilidad filtradísima por la moral y por las imposiciones simbólicas que dan persistencia a la institución familiar declarada en la prohibición del incesto:

3 REICH, 1985. Consultar especialmente el capítulo 5: "La familia autoritaria como aparato de educación". 
El fin del tabú del incesto y la abolición de la familia tendrá como efectos la liberación sexual y la liberación consecuente de la cultura (MILLET, 1995, p. 79)

Abolir el capitalismo no significa la abolición de la tradición patriarcal mientras se conserve la familla. Yo no creo solamente que se deba abolir el capitalismo y cambiar los medios de producción. También hace falta un cambio en la estructura familiar. Y eso no sucedió ni siquiera en China. Insisto en que hay que abolir la familia y reemplazarla por formas nuevas (Extracto de "Conversaciones con Simone de Beauvoir" en la revista Crisis, n” 42, mayo del 86)

Es bastante evidente que las relaciones amorosas que conocemos, son más bien insatisfactorias y primera causa de quiebra de la estabilidad mental y de búsqueda profesional medicalizada. Esto no es nada extraño si entendemos que aprendemos el amor de la crianza. No se trata de culpabilizar a la madre, y ni siquiera el padre sino de señalar que el cautiverio al que se somete a la mujer al hacerse madre, se impone también sobre los niños, de tal manera que conocen las relaciones sociales, auténticas, completas y no filtradas por la autoridad paternal, muy tardíamente, después incluso de que su personalidad se haya configurado. Esto hace que la empatía hacia los demás sea estrechísima. Esto no cambia sino aboliendo la familia y abriéndonos hacia formas de crianza menos autoritarias, más horizontales y a modos de parentesco no basados en el lazo sexual y la consanguinidad .

El malestar de la mujer, su sensación de estar siendo abusada, aun con su consentimiento, así como el miedo del hombre a un reparto insatisfactorio en el intercambio de mujeres, hallan una solución común en la construcción simbólica del negro y del inmigrante, como portador de un peligro machista y violento, que, imaginariamente, hubiera sido conjurado en la civilización blanca. Actualmente asistimos a la exotización del machismo, a través de una enorme insistencia mediática de difamación de las culturas islámicas, de la valoración desigual con la que se juzgan las letras y ritmos de la música racializada, etc.

... el mito del violador negro fue una invención claramente política (...) En el periodo inmediatamente posterior a la guerra civil, el espectro amenazante del violador negro aún no había hecho su aparición en el panorama histórico. Pero los linchamientos, reservados durante la esclavitud para los abolicionistas blancos, se demostraron una valiosa arma política. Y, antes de que el linchamiento se pudiera consolidar como una institución popularmente aceptada, había que justificar convincentemente su salvajismo y sus horrores. Éstas fueron las circunstancias que alumbraron el mito del violador negro, puesto que la acusación de violación se reveló el medio más poderoso, de todos los intentos que se hicieron, para justificar el linchamiento de las personas negras (DAVIS, 2005, p. 186). 


\section{Violencia de género, desatención e indefensión. Más allá del perfil del maltratador.}

En los últimos tiempos, la violencia de género se ha extendido casi hasta la normalización. No es casual ni se trata de una degradación de las personas. Las agresiones se visibilicen bajo discursos e interpretaciones inadecuados. El relato de la vulnerabilidad de la mujer en las relaciones interpersonales en las que se halla inmersa, se construye como alerta de peligrosidad social, contribuyendo a un nuevo aislamiento de la mujer, incremento de represión policial y endurecimiento penitenciario, que en nada mejoran las condiciones materiales en las que se constituyen las subjetividades sino que fortalece las relaciones de abuso, en las que se inserta la violencia de género y de las que se alimenta.

Existen, al menos, dos ideologías dominantes cubriendo los hechos mencionados y fundándolos de modo totalmente pernicioso. Por un lado, encontramos el diseño irreal del perfil del maltratador, a través del cine, la crónica periodística y su amplificación en el tejido de las redes sociales. Aparece como un hombre locamente enamorado, muy presente, con miedo a perder a su pareja, acomplejado y con poco carisma. La sintomática sería: exceso de atención, disponibilidad continua, demanda de amor y alta emocionalidad. Este perfil tan cinematográfico, sin embargo, es un mito, tal vez un deseo del imaginario romántico insertado en la mujer, que la dispone a esperar y a entregar. La realidad es que el maltrato de género se acompaña generalmente de una actitud mucho más desapegada y desvalorizante, más cercano al abandono, a la inestabilidad, a la desatención, falta de escucha y consideración unidimensionalizada de la mujer en clave sexual. El hecho de pensar al maltratador como un perdedor acomplejado, que se agarra a su pareja y que vierte en ella sus frustraciones, pone en peligro la credibilidad de la mayor parte de mujeres que sufren las formas más notables de violencia a manos, casi siempre, de hombres muy bien aceptados socialmente, populares, exitosos y huidizos. Desde esta posición, podremos entender que no todos los hombres violentos, y ni siquiera la mayoría, sienten el impulso de coartar la libertad de las mujeres con las que mantienen relaciones, prohibiéndoles hacer cosas, salir, disfrutar de sus amistades y aficiones, etc. Son muchos más los que sienten el impulso de coartar la libertad de las mujeres con las que mantienen relaciones haciéndose esperar, de tal manera que las mujeres pudiendo salir, disfrutar de sus amistades y aficiones sin trabas, no pueden, porque al encontrarse a la espera de un mensaje, de una confirmación, de un "te quiero", de un rato en su agenda, de una decisión firme o de cualquier signo de atención, no disfrutan de sus amistades y aficiones, pues con la mente puesta en un futurible incierto, sienten mariposas en su estómago (que no es 
síntoma de amor sino simplemente de ansiedad). Esta estrategia triunfa muy por encima de la represión clásica. Los discursos de la igualdad y la reciprocidad suelen ser discursos liberadores, mientras que, paradójicamente, los discursos de la libertad y de la independencia, suelen ser discursos de explotación, en este caso, de explotación afectiva. Una deriva neoliberal muy mercantilista, se abre en este intento de ligar la figura del maltratador al apego y a la atención, que está arrojando a las mujeres a la aceptación de relaciones sentimentales en las que no hay ni cuidado, ni interés por la persona, ni afecto ni nada de lo que constituye el complejo del amor.

Por otro lado, los espiritualismo psudo-orientalistas, tipo new age, están haciendo estragos en el lenguaje y, por ello, en el modo en que sentimos, percibimos la realidad y nos hacemos cargo de nuestras relaciones afectivas. Intensifican también el giro neoliberal de las recetas sobre el cuidado de sí, mezclando una suerte de determinismo cósmico al que hubiera que doblegarse, con un voluntarismo extremo que individualiza absolutamente los aconteceres de cada persona. Bajo este panorama, una enfermedad revela una culpa en el alma, un fracaso laboral, un exceso de apego que debe ser contrarrestado con una oportunidad que el cosmos nos da para crecer en autonomía y emprendimiento, y una relación sexo-afectiva violenta en una oportunidad para ver en el otro los propios defectos y aprender a establecer relaciones menos "tóxicas". Son muchas las mujeres que, siendo físicamente maltratadas, no son consciente siquiera, pues observan y padecen toda agresión como drama erótico. Acaban por decidir que tienen una "relación tóxica", concepto que se libra de todo análisis de desigualdad social, privilegios sexuales y raciales y que desdibuja la diferencia entre el agresor y la víctima. Esta sensación de toxicidad resulta, además, adictiva y, en cierto punto, atractiva.

Erotizar Ia dominacion y Ia sumisión crea el genero ... Bajo el dominio de la supremacía masculina, lo erótico es lo que define el sexo como desigualdad, esto es, como diferencia significativa. La objetivizacion sexualizada es lo que define a las mujeres como, y únicamente como sexuales (MACKINNON, 2014, p. 210)

Creo que en las mujeres, al menos en esta cultura, el deseo sexual se ha construido socialmente como aquello por lo que llegamos a desear nuestro propio autoaniquilamiento. Esto es, nuestra subordinación es erotizada precisamente en tanto femenina ... (MACKINNON, 2014, p. 210)

Si bajo el lema de la liberación sexual, se extendió la mercantilización e intercambio masivo de las mujeres, bajo un consentimiento forzado de las mismas ante la desalentadora consecuencia de no lograr nunca ser amadas, aceptadas, deseadas o, incluso, reconocidas, y se 
instauró sobre ellas la casi permanente disponibilidad al sexo, la comunidad de mujeres que Marx criticaba en los modos de vida burgueses, se habrá extendido a lo largo de todas las capas sociales, apenas sin transformaciones.

Cuando una mujer acepta lo que sería violación si no la aceptara, lo que ocurre es sexo (MACKINNON, 1995, p. 285).

Todas las mujeres viven en la objetivación sexual como los peces viven en el agua. Todas las mujeres viven siempre bajo la sombra de la amenaza del abuso sexual. La pregunta es qué significa vivir como mujer, qué significa el sexo para las supervivientes en una cultura de la violación"", "El supuesto de que en cuestiones sexuales las mujeres en realidad quieren lo que los hombres quieren de las mujeres hace que la fuerza masculina contra las mujeres en el sexo sea invisible (MACKINNON, 1995, p. 285).

Si observamos la permanencia de los más inauténticas trampas del victorianismo en la separación entre la vida personal y la vida política (laboral, artística, activista, militante, etc.), nos daremos cuenta de que la hipocresía, el secretismo y el disimulo conforman, mucho más que reminiscencias, los códigos actuales que siguen rigiendo más violentamente que nunca, una vez que las personas cruzan el límite de la adolescencia. El lema feminista según el cual, lo personal es político, no ha calado siquiera entre los grupos más concienciados y el "derecho a la vida privada" (de los hombres, ya que las mujeres no la tienen o es lo único que tienen) retorna en un juego malintencionado que soborna eficazmente a la mujer para seguir ocultando, por pudor, por elegancia, por estatus, las humillaciones a las que ha sido sometida. La clandestinidad de las relaciones sexuales se ha impuesto y el silencio de la mujer, se han impuesto. La expropiación del relato de sus vivencias, de la posibilidad de contrastar sus experiencias en la vida social, de la llorabilidad de los duelos y, en definitiva, de su propio cuerpo y de su propia historia, en beneficio de la discreción, allana el terreno masculino para el donjuanismo pero, sobre todo, para la negación de la vida de la mujer y para el disimulo de la violencia sobre ella.

No es difícil comprobar que la sexualidad construye los géneros, pues los género no son solo roles sino una desigualdad basal en los roles y estos roles se despliegan, fundamentalmente en la vida sexual y los rituales que la rodean y le dan escena:

Igual que la expropiación organizada del trabajo de algunos en beneficio de otros, define una clase, la de los trabajadores, la expropiación organizada de la sexualidad de unos para el uso de otros, define un sexo, la mujer (MACKINNON, 1995, p. 24) 
Practicar sexo con los desposeídos de poder es una forma de seguir teniéndolo, afirmación de jerarquía que sigue haciéndolo sexy en un sistema sexual en que la jerarquía es sexy (MACKINNON, 1995, p. 363)

\section{Abolición de la familia y laboralización del trabajo afectivo de las mujeres.}

A modo de conclusión, quisiéramos insistir en la necesidad de abolir/aflojar la institución familiar, levantar la prohibición del incesto y reconocer el carácter productivo del trabajo doméstico y afectivo que, tradicionalmente, han ejercido las mujeres $\mathrm{u}$ otros colectivos oprimidos por la racialización, la exotización o la circunstancia migrante, incluyendo el trabajo sexual. La generalización de la prostitución bajo motivos inconscientes y chantajes emocionales de todo tipo, nos permite abrirnos al problema de la prostitución, identificándonos en ella en lugar de exteriorizarla y extrañarla de nuestros cuerpos, como si las condiciones obscuras de la mayor parte de las transacciones, eliminaran la naturaleza explotada, involuntaria e incluso traumática de la vivencia sexual de la mujer, que es, a menudo, la vivencia de una impostura que nos aleja de la conciencia de género. Se puede tener conciencia de género oprimido sin tener que identificarse con la opresión que nos re-escribe como mujeres.

Queremos llamar trabajo al trabajo para que así eventualmente podamos redescubrir lo que es amar y crear nuestra propia sexualidad, aquella que nunca hemos conocido. Y, desde el punto de vista laboral, podemos reclamar no solo un salario sino muchos salarios, puesto que se nos ha forzado a trabajar de muchas maneras. Somos amas de casa, prostitutas, enfermeras, psicoanalistas... (FEDERICI, 2013, p. 41).

Fingir excitación durante el acto sexual, en ausencia del orgasmo, también es un trabajo, y uno duro, porque cuando finges nunca sabes hasta dónde deberías llegar y siempre acabas haciendo más de lo que deberías (FEDERICI, 2013, p. 49).

Sin modos de crianza, subjetivación y socialización más amplios, más allá del secuestro que la familia significa para los niños y que se impone con más brutalidad en tanto los espacios urbanos e incluso rurales han dejado de ser espacios comunitarios y seguros para ser espacios de guerra, ocupados y atravesados por las formas más grotescas de dominación y agresión, sin alternativas no familiaristas en el tejimiento de redes de apoyo social, sin reconocimiento de parentescos fundados en la libre elección amistosa y sin recursos colectivos de sublimación que permitan desplazar la fantástica preponderancia del sexo como lugar privilegiado de subjetivación, de intercambios, de autovalorización y de medición de la fuerza y salud de nuestras personalidades, se hace imposible abandonar el terreno de explotación y alienación en 
la que nos encontramos. Construir los escenarios que nos permitan descubrir y reimpulsar nuestra capacidad deseante, nuestros placeres, nuestra capacidad para vivir auténticamente el amor, el mutuo entiquecimiento personal, así como el arte de estilizarnos y de diferenciarnos como individuos, pasa por la construcción de nuevos códigos y valores que den sentido a una realidad en la que la familia, de hecho, ya ha fracasado y ya se ha descompuesto.

\section{Bibliografía}

DAVIS, A. Mujeres, raza y clase. Ed. Akal. Madrid, 2005.

DELEUZE, G. En medio de Spinoza. Ed. Cactus. Buenos Aires, 2006.

ENGELS, F. El origen de la familia, la propiedad privada y el Estado. Ed. Progreso. Archivo Marx-Engels de la Sección en Español del Marxists Internet Archive 2017.

ENGELS, F. La situación de la clase obrera en Inglaterra. https://www.marxists.org/espanol/me/1840s/situacion/situacion.doc

LÉVI-STRAUSS, J. C. Las estructuras elementales del parentesco. Ed. Paidós. Barcelona, 1998.

FAUSTO-STERLING, A. Cuerpos sexuados. La política de género y la construcción de la sexualidad. Ed. Melusina. Barcelona, 2006.

Federici, S. Calibán y la bruja. Ed. Traficantes de sueño. Madrid, 2010.

Federici, S. Revolución en punto cero. Trabajo doméstico, reproducción y luchas feministas. Ed. Traficantes de sueños. Madrid, 2013.

Firestone, S. La dialéctica del sexo. En defensa de la revolución feminista. Ed. Kairós. Barcelona 1976.

HEIDEGGER, M. Conferencias y artículos. Ed. del Serval. Barcelona, 2001.

MacKinnon, C. A. Feminismo inmodificado. Discurso sobre la vida y el derecho. Ed. Siglo XX. Buenos Aires, 2014.

MACKINNON. Hacia una teoría feminista del Estado. Ed. Cátedra. Madrid, 1995)

MARX, K. El capital. http://aristobulo.psuv.org.ve/wpcontent/uploads/2008/10/marx-karl-el-capital-tomo-i1.pdf

MARX, K. Manuscritos de París. http://www.rebelion.org/noticia.php?id=21429

MARX, K; ENGELS, F. Manifiesto del Partido Comunista. Ed. Fundación de 
Investigaciones Marxistas. Madrid, 2013.

MILLET, Kate. Política sexual. Ed. Cátedra. Madrid, 1995.

REICH, W. La revolución sexual. Para una estructura de carácter autónoma del hombre. Ed. Planeta de Agostini. Barcelona, 1985.

SPINOZA, B. Ética. Ed. Alianza. Madrid, 1987.

Wittig, M. El pensamiento heterosexual. Ed. Egales. Bercelona, 2006. 